\title{
Clinical study of uterine Leiomyoma and its associated risk factors
}

\author{
Sunita Sudhir $\mathbf{P}^{1}$, Madhavi $\mathbf{N}^{2}$, Nissy Jacintha ${ }^{3}$ \\ ${ }^{1}$ Dr Sunita Sudhir P, Associate Professor, ${ }^{2}$ Dr Madhavi N, Professor, ${ }^{3}$ Dr Nissy Jacintha, Assistant Professor, all authors are \\ affiliated with Department of Obstetrics and Gynaecology, Kamineni Institute of Medical Sciences, Narketpally, Telangana \\ State, India.
}

Address for Correspondence: Dr Sunita Sudhir. P, Associate Professor, Department of Obstetrics and Gynaecology, Kamineni Institute of Medical Sciences, Narketpally, Telangana State, India. E-mail: sunitadr@rediffmail.com

\begin{abstract}
Introduction: Uterine leiomyomas have historically been viewed as major indication for hysterectomy. As new therapies have developed, the heterogeneity of this disease has become therapeutically relevant. An awareness of the role of risk factors, growth factors, hormones and genetics in tumor etiology is the key to understanding of this disease. This study was undertaken to know the various risk factors associated with uterine leiomyoma. Objective: To Study the clinical features and various risk factors associated with leiomyoma of uterus. Materials and Methods: This is a hospital based prospective study of 55 uterine leiomyoma cases. After taking consent all cases were enrolled into the study and detailed history regarding mode of presentation, clinical features and various risk factors of uterine leiomyoma was taken, all cases underwent transvaginal ultrasound to know the location of leiomyoma. Specimen of leiomyoma was sent for histopathological examination and analysed. Results: Mean age group of the cases was between $41-50$ years. Mean age at menarche was 12.9 years. Maximum numbers of cases were in the group of PARA - 2. Abnormal uterine bleeding like Menorrhagia, Polymenorrhea, Metrorrhagia, and Dysmenorrhea were the most common modes of presentation followed by pain and increased urinary frequency. In the present study $49.09 \%$ of subjects were above normal BMI range. Individuals with sedentary life style were at higher risk of developing leiomyoma. Intramural was the commonest location of fibroid followed by subserosal and submucus fibroids. On Histopathological examination, leiomyoma was confirmed and Cervicitis was the most common accompanying feature followed by adenomyoisis and degeneration. Conclusion: Leiomyoma of uterus is multifactorial in origin with various factors acting in conjunction. Increased oestrogen exposures due to factors modulate myometrial cells and act as tumor promoters. Reproductive age of patient, early menarche, obesity and parity are most common risk fctors which modulate estrogen response.
\end{abstract}

Keywords: Uterine Leiomyoma, Menorrhagia, Dysmenorrhia, Cervicitis, Adenomyosis Degeneration

\section{Introduction}

Leiomyoma or uterine fibroids are the most common benign solid tumors to afflict women during their reproductive years. In spite of high prevalence, fibroids still remain enigmatic, incidence and progression of which is incompletely understood. Fibroids are the most frequent indication for hysterectomy, causing enormous health and financial burden.

Less than $50 \%$ patients with fibroids are symptomatic. As fibroids can occur at various sites like Intramural, subserous, submucus, symptoms due to fibroid uterus may be single or multiple depending upon the size, site, numbers and concomitant degenerative changes in fibroid $[1,2]$. Even though they are benign, fibroids cause

\footnotetext{
Manuscript received: $7^{\text {th }}$ December 2016

Reviewed: $15^{\text {th }}$ December 2016

Author Corrected: $24^{\text {th }}$ December 2016

Accepted for Publication: $31^{\text {st }}$ December 2016
}

Obsgyne Review: Journal of Obstetrics and Gynecology reproductive problems such as, heavy and abnormal uterine bleeding, uterine enlargement, pelvic pressure, severe cramping pain, infertility and miscarriages thus causing substantial morbidity. It is however surprising that no significant data is still available to give a clear idea as to what is the major cause of fibroids $[3,4]$.

The incidence of uterine fibroids increases as women grow old, and they may occur in more than 30 percent of women between the age group of 40 to 60 years. Risk factors include nulliparity, obesity, family history, black race, and hypertension. Leiomyomas can occur at various anatomical sites, uterus being the commonest of all and in the uterus it can be, intramural, submucus, subserosal, and cervical [5]. Clinical sequel of leiomyomas depend on their location in the uterus, may be associated with irregular bleeding, intermenstrual bleeding, causing 
Original Research Article

anemia, leiomyomas also have been associated with abortion, preterm labour infertility. $0.1 \%$ of cases go in for malignant change known as leiomyo sarcoma [3,4].

\section{Aims and Objectives}

1. To study the clinical features of uterine leiomyoma

2. To identify the risk factors associated with leiomyoma uterus.

\section{Materials and Methods}

Study Design: Prospective observational study.

Study Sample: 55

Place Of Study: Kamineni institute of medical sciences, Narketpally.

\section{Inclusion Criteria}

1) Women in reproductive age group diagnosed to have fibroid uterus by ultrasonography.

2) Patient having menorrhagia secondary to fibroid uterus.

3) Patient undergoing hysterectomy or myomectomy for fibroid uterus.
4) Patient willing to give consent for enrolment in the study.

\section{Exclusion Criteria}

1) Patients having other pelvic pathologies.

2) Patients on hormonal replacement therapy (HRT).

3) Patients on treatment for carcinomas eg. breast cancer.

4) Postmenopausal women having fibroid

Methodology: Selected patients were informed about the study, written consent was taken and then enrolled into the study. Clinical presentation and risk factors, were analyzed by taking detailed medical, personal and family history in a specifically designed proforma.

Patients were subjected to investigations like transvaginal ultra-sonography scan to confirm the location of fibroid, surgical profile.

All patients were managed with appropriate surgery according to standard hospital protocol. Post surgery the hysterectomy/ myomectomy specimen was sent for histopathological examination and leiomyoma confirmed.

\section{Results}

Age: In the present study all the patients were in the range of 25 -55 years. Maximum numbers of patients were in the age group of 41 - 50 years, accounting for $63 \%$ of all cases. Youngest patient in our study was of 29 years age oldest patient in our study was of age 54 years.

Mean age of the patients was:- 44 years; $\operatorname{SD}(\sigma)= \pm 5.81$

Table No 1: Age Group Distribution $(n=55)$.

\begin{tabular}{|c|c|c|}
\hline Age group & $\begin{array}{c}\text { No. of patients } \\
\mathbf{N = 5 5}\end{array}$ \\
\hline $\mathbf{2 5 - 3 0}$ & 1 & 1.81 \\
\hline $\mathbf{3 1}-\mathbf{3 5}$ & 5 & 9.09 \\
\hline $\mathbf{3 6}-\mathbf{4 0}$ & 9 & 16.36 \\
\hline $\mathbf{4 1}-\mathbf{4 5}$ & 14 & 25.45 \\
\hline $\mathbf{4 6}-\mathbf{5 0}$ & 21 & 38.18 \\
\hline$>\mathbf{5 0}$ & 6 & 10.90 \\
\hline
\end{tabular}

Menarche: Mean age at menarche was: 12.927 years; SD $(\sigma)= \pm 0.74$

Menarche Age range was: 10 -16 years

Parity: 30 (54.54\%) cases were in para 2 group, followed by 14 (25.45\%) cases of para 3 group. Woman of highest parity was of para 6 and in the group of para 1 there were 6 cases.

Combined total of Para -1 and Para -2 cases accounted for of $65.45 \%$.of cases.

ie $(\mathrm{P} 1=6)+(\mathrm{P} 2=30)=36 / 55 \times 100$ 
Table No.-2: Clinical Presentation.

\section{Original Research Article}

\begin{tabular}{|c|c|}
\hline Presentation & No. of cases \\
\hline Menstrual Symptoms & $47(85.45 \%)$ \\
\hline Pain Abdomen & $8(14.54 \%)$ \\
\hline Mass Per Abdomen & $6(10.90 \%)$ \\
\hline Urinary Symptoms & $5(9.09 \%)$ \\
\hline
\end{tabular}

Most common mode of presentation was related to menstrual symptoms. 47 cases presented with menstrual symptoms and 8 cases presented with history of pain abdomen.

Table No 3: Menstrual Symptoms (n=47).

\begin{tabular}{|c|c|}
\hline Menorrhagia & $26(47.27 \%)$ \\
\hline Metrorrhagia & $3(5.4 \%)$ \\
\hline Polymenorrhea & $7(12.7 \%)$ \\
\hline Dysmenorrhea & $5(9.09 \%)$ \\
\hline Intermenstrual Bleeding & $6(10.90 \%)$ \\
\hline
\end{tabular}

Out of 47 patients who had menstrual symptoms, menorrhagia (47.27\%) was the most common type of menstrual irregularity observed.

Duration of Symptoms: In our study duration of the disease with respect to chief complaints was evaluated.

Table No 4: Duration of Symptoms $(n=55)$.

\begin{tabular}{|c|c|}
\hline Duration of symptoms & No. of cases \\
\hline$<1$ Month & 3 \\
\hline $1-3$ Month & 13 \\
\hline $3-6$ Months & 9 \\
\hline $6-9$ Months & 8 \\
\hline $9-12$ Months & 12 \\
\hline $1-2$ Years & 5 \\
\hline$>2$ Years & 3 \\
\hline
\end{tabular}

It was observed that most of the patients presented to Gynaecology OPD between 3 months to 1 year. Some patients presented late due to symptomatic management of menstrual symptoms with local doctors. Ignorance and lack of awareness also plays an important role in time duration of disease and presentation of case.

Smoking: In our study none of the patients had history of smoking.

Obesity: We correlated the incidence of fibroid and obesity with respect to Body Mass Index (BMI). BMI was calculated by using body weight and height. BMI $=$ Weight $(\mathrm{In} \mathrm{Kg}) /$ Height $^{2}$ (In Meters).

\section{Obesity was graded as:}

Normal: BMI 18.5 - 24.99

Over weight: BMI 25 - 29.99

Obese: $\mathrm{BMI}>30$ 
Original Research Article

Table No 5: Obesity

\begin{tabular}{|c|c|}
\hline Obesity & No. of Patients \\
\hline Normal & $28(50.9 \%)$ \\
\hline Over weight & $17(30.90 \%)$ \\
\hline Obese & $10(18.18 \%)$ \\
\hline
\end{tabular}

In our study $50.9 \%$ of patients, were with in normal range of BMI. $49.08 \%$ of cases crossed the normal BMI range

OCP Use: OCP use has been linked with the incidence of fibroid. In our study 5 out of 55(9.09\%) cases gave history of OCP use, and all of the above were irregular users and Details of most commonly used OCP were unavailable.

Family History: Genetic linkage with occurrence of fibroids has been widely accepted.In this study 13 out of 55 patients had positive family history of fibroids. And 5 patients had positive family history in their first degree relatives.

Life Style: Sedentary life style has been more commonly associated with leiomyoma uterus. In the present study $60 \%$ of cases had sedentary life style remaining $40 \%$ of cases were leading an active life style.

Ultrasound Examination: All selected cases under went transvaginal ultrasound for confirmation of leiomyoma, distribution and location of fibroids was noted. Intramural location was the most common site of fibroids seen in $48(87.27 \%)$ cases, in 4(7.2\%) cases fibroid was subserosal and in 3(5.4\%) cases submucosal in location. Out of 55 cases studied 32 cases had solitary fibroid and 22 cases had multiple fibroids.

Histopathological Examination: In all cases, leiomyoma was confirmed by histopathological examination of the hysterectomy /myomectomy specimen. Associated histopathological findings were noted. Cervicitis was the most common histopathological change associated with fibroids, seen in 27 cases followed by adenomyosis and degenerative changes.

Table No 6: Associated Histopathological changes. $(n=55)$.

\begin{tabular}{|c|c|}
\hline Histopathology & $\mathrm{n}=\mathbf{5 5}(\%)$ \\
\hline Adenomyosis & $18(32.70 \%)$ \\
\hline Cervicitis & $27(49.09 \%)$ \\
\hline Degenerative changes & $10(18.18 \%)$ \\
\hline
\end{tabular}

\section{Discussion}

This is a prospective case control study in which a total of 55 cases with uterine leiomyoma and 55 age matched controls, free of uterine leiomyoma were studied.

All cases underwent routine surgical work up, detailed history was taken in all cases with respect to reproductive factors, risk factors, and cases were treated as per surgical protocol. Surgical specimen was sent for histopathological examination. Data collected during the study was analysed.

Age- In our study $63 \%$ of patients were in the age group of 41-50years. Mean age at presentation was of 44 years $\mathrm{SD}(\sigma) \pm 5.81$. It was similar to an earlier study conducted by Faerestein et al (2001) where mean age at presentation was 43.3 years and maximum patients were in the age group of 40-49 years [6].

Obsgyne Review: Journal of Obstetrics and Gynecology
Menarche: Mean age at menarche of cases in our study was 12.9 years which was almost similar to that of Faerestein et al(2001) [6] where mean age of menarche was 12.4 years.

Parity: In present study it was found that most of the women were of para-2, 67\% of the cases were combined para - 1 and para - 2. One case of para -6 was found to have a strong positive family history. Faerestein et al(2001) [6] observed 55\% of cases in para 1 and Para 2 group, the difference in this percentage might be attributed to the smaller sample size we studied.

Presentation: In our study menstrual symptoms like menorrhagia, metrorrhagia, polymenorrhagia, dysmenorrhea were the most common presenting symptoms seen in $85.45 \%$ of cases. Among menstrual symptoms, menorrhagia was the most common presenting

Available online at: www.medresearch.in

52 | $P$ a g e 
Original Research Article

symptom seen in 26 cases $(47.27 \%)$, followed by pain abdomen (14.54\%), urinary symptoms $(10.90 \%)$ and mass per abdomen $(9.09 \%)$. An earlier study of Nuruddin et al(2002) [7] Similarly observed abnormal uterine bleeding as the most common presenting symptom in fibroid patients, seen in $74.1 \%$ of cases followed by pain seen in $29.3 \%$ of cases.

Duration of Symptoms: Most of the patients presented within 3 months to 1 year of the onset of symptoms. Late presenters were either having minimal symptoms or were taking symptomatic treatment for abnormal uterine bleeding. In our study we observed that patients with pain and increased urinary frequency presented early as compared to those with menorrhagia. The cases presented in this study much earlier than that reported by Nuruddin et al (2002) [7] who observed $1-3$ years as most common mean duration of symptoms. Earlier presentation of cases in our study could be due to increased awareness and education in the population.

Obesity: Obesity is considered to be risk factor for uterine leiomyoma. Shikora et al.(1991) [8] in their study observed $51 \%$ of the hysterectomy- or myomectomyconfirmed patients with leiomyomata were overweight, and $16 \%$ were severely obese. In our study we correlated a similar incidence of fibroid and obesity with respect to BMI and observed $50.9 \%$ of patients with in normal range of BMI. $49.08 \%$ of cases crossed the normal BMI range ( $30.9 \%$ overweight $+18.18 \%$ Obese $)$.

Smoking: Several studies have revealed that smokers have reduced risk of fibroids. (Michnovicz et al. 1986) [9]In our study none of the patients gave history of smoking.

Family History: Positive family history has been considered to have an increased incidence of fibroids. In our study 13 out of 55 patients $(23.63 \%)$ had positive family history of fibroids and five of them had a first degree relative with fibroids which is less when compared to the study conducted by Schwartz et al.(2000b) [10] where 638 patients were studied and $33.2 \%$ of patients had a positive family history of fibroids. This difference may be because older family members of women in our cohort were not screened for gynaecological disorders.

Life Style: Sedentary life style is more commonly associated with leiomyoma uterus. Frisch et al.(1985) [11] and Wyshak et al.(1986) [12] reported that patients having an active life style have a less chance of developing fibroids as compared to Patients, leading a sedentary life style. Similar history was observed in our study where $60 \%$ of cases had a sedentary life style.
Ultrasound Examination: Nuruddin et al (2002) [7] found most common location of fibroids was intramural (55.3\%), followed by subserosal and least common was submucus fibroid, while Faerestein et al(2001) [6] also observed intramural location as a common site of fibroids, which was seen in $42.3 \%$ of cases followed by subserosal, where as we observed $87.27 \%$ of fibroids in the intramural location followed by subserosal and submucus, this difference in percentage in may be due to the smaller sample size included in this study.

Histopathological Examination: In all cases leiomyoma was confirmed by histopathological examination and the most common accompanying feature observed was cervicitis followed by adenomyosis and degeneration. Nuruddin et al ( 2002) [7] also observed similar features in his study.

Overall this preliminary study of uterine leiomyomata or uterine fibroids indicates that obesity, sedentary life style and family history attribute to the risk of developing fibroids.

\section{Conclusion}

From this study we conclude that uterine leiomyoma is a disease of complex etiology and multifactorial in origin, no single factor can be pin pointed. Among all, Reproductive age of patient, early menarche, obesity and parity play an important role in occurrence of uterine leiomyoma, they act as promoters of the tumor.

Basic pathology behind these risk factors is that they increase the estrogen exposure of the target uterine myometrium and may increase the number of cell divisions resulting in increased chance of mutation in genes controlling myometrial cell proliferation.

Funding: Nil, Conflict of interest: Nil

\section{References}

1. Lesley LB, John AR, leiomyomatn uteri and myomectomy.Te lindes operative gynaecology $9^{\text {th }}$ edition; Lippincott Williams and wilkinsons 2003:753-798.

2. Lumsden MA, Wallace EM. Clinical presentation of uterine fibroids. Baillieres Clin Obstet Gynaecol. 1998 Jun; 12(2):177-95.

3. Sandberg AA. Updates on the cytogenetics and molecular genetics of bone and soft tissue tumors: leiomyoma. Cancer Genet Cytogenet. 2005 Apr 1;158 (1): $1-26$. Permission from IRB: Yes 
4. Cramer SF, Patel A. The frequency of uterine leiomyomas. Am J Clin Pathol. 1990 Oct; 94(4):435-8.

5. Flake, Gordon P, Janet Anderson, Darlene Dixon. Etiology and pathogenesis of uterine leiomyoma- A review; Environment health perspect 2003; 111: 1037 1054.

6. Farestien E, Moyses Szklo, Neil Rosenshein. Uterine leiomyoma a practice based case control study- African American heritage, reproductive history, body size and smoking. American Journal of Epidemiology 2001;153 (1): $1-10$.

7. Mohammed NB, NoorAli R, AnandaKumar C. Uterine fibroid: clinical presentation and relative morbidity of abdominal myomectomy and total abdominal hysterectomy, in a teaching hospital of Karachi, Pakistan. Singapore Med J. 2002 Jun;43(6):289-95.

8. Shikora SA, Niloff JM, Bistrian BR, Forse RA, Blackburn GL. Relationship between obesity and uterine leiomyomata. Nutrition. 1991 Jul-Aug;7(4):251-5.

\section{Original Research Article}

9. Michnovicz JJ, Hershcopf RJ, Naganuma H, Bradlow HL, Fishman J. Increased 2-hydroxylation of estradiol as a possible mechanism for the anti-estrogenic effect of cigarette smoking. N Engl J Med. 1986 Nov 20; 315 (21): 1305-9.

10. Schwartz SM, Voigt L, Tickman E, Yarbro P, Daling J, Scholes D.Familial aggregation of uterine leiomyomata. Am J Epidemiol 2000b; 151:5-10.

11. Frisch RE, Wyshak G, Albright NL, Albright TE, Schiff I, Jones KP, Witschi J, Shiang E, Koff E, Marguglio M. Lower prevalence of breast cancer and cancers of the reproductive system among former college athletes compared to non-athletes. Br J Cancer. 1985 Dec; 52 (6):885-91.

12. Wyshak G, Frisch RE, Albright NL, Albright TE, Schiff I. Lower prevalence of benign diseases of the breast and benign tumours of the reproductive system among former college athletes compared to non- athletes. Br J Cancer 1986;54:841-845.

\section{How to cite this article?}

Sunita Sudhir P, Madhavi N, Nissy Jacintha. Clinical study of uterine Leiomyoma and its associated risk factors. Obs Rev:J obstet Gynecol 2016;2(4):49-54.doi: 10.17511/joog.2016.i04.02. 